\title{
Síndromes de dispersão na maior área de proteção da Mata Atlântica paraibana
}

\author{
Camila Ângelo Jerônimo Domingues \\ Vanessa Gabrielle Nóbrega Gomes \\ Zelma Glebya Maciel Quirino * \\ Universidade Federal da Paraíba, Departamento de Engenharia e Meio Ambiente \\ Rua da Mangueira, s/n, Campus IV, CEP 58297-000, Rio Tinto - PB, Brasil \\ * Autor para correspondência \\ zelmaglebya@gmail.com
}

Submetido em 16/08/2012

Aceito para publicação em 24/04/2013

\section{Resumo}

O processo de dispersão de diásporos é crucial para a reprodução dos vegetais, pois eles devem chegar a um local propício para germinar. O objetivo deste artigo foi estudar aspectos morfológicos dos diásporos e determinar as síndromes de dispersão das espécies ocorrentes na maior área de proteção na Mata Atlântica paraibana, a Reserva Biológica Guaribas. Foi realizada coleta de frutos/sementes mensalmente no período de setembro de 2007 a fevereiro de 2009. Todos os diásporos das espécies em frutificação foram coletados. Após analisar características como consistência do fruto e semente, odor, cor, tamanho e peso foi determinada a síndrome de dispersão de cada espécie. Foram coletados 3.080 diásporos pertencentes a 136 espécies diferentes distribuídas em 27 famílias. A síndrome de dispersão mais abundante foi a zoocoria (58\%, com 79 frutos adaptados a ela), seguida pela autocoria $(29 \%)$ e pela anemocoria (13\%). Durante todo o período do estudo foram encontradas espécies em frutificação, com predominância de frutos zoocóricos, um fato previsível na Mata Atlântica, que disponibiliza frutos carnosos durante todo o ano.

Palavras-chave: Diásporo; Morfologia dos frutos; Zoocoria

\section{Abstract}

Dispersal syndromes in the largest protection area of the Atlantic Forest in the state of Paraiba, Brazil. The diaspore dispersal process is crucial for plant reproduction, since the diaspores must reach a suitable site to germinate. This paper aimed to study morphological aspects of diaspores and determine the dispersal syndromes of species occurring in the largest protection area of the Atlantic Forest in the state of Paraiba, Brazil, the Guaribas Biological Reserve. One conducted a monthly collection of fruits/seeds within the period from September 2007 to February 2009. All diaspores of the fruiting species were collected. After analyzing characteristics such as fruit and seed consistency, odor, color, size, and weight, one determined the dispersal syndrome of each species. One collected 3,080 diaspores belonging to 136 different species distributed into 27 families. Zoochory was the most abundant dispersal syndrome (58\%, with 79 fruits adapted to it), followed by autochory (29\%), and anemochory (13\%). Throughout the study period, one found fruiting species, with a predominance of zoochoric fruits, a predictable fact in the Atlantic Forest, which provides fleshy fruits all the year round.

Key words: Diaspore; Morphology of fruits; Zoochory 


\section{Introdução}

A dispersão de sementes é uma das etapas mais delicadas da reprodução vegetal, pois estas devem chegar a um local propício para germinar, longe ou não da planta-mãe, reduzindo a competição e o risco de predação (HOWE, 1993). Esse é um dos processos mais importantes da regeneração natural de florestas tropicais, assim como da colonização de novos habitats (PIJL, 1982). Essa colonização desempenha um papel fundamental no estabelecimento, desenvolvimento e evolução das espécies florestais, permitindo, assim, o intercâmbio de material genético intra e interpopulacional (RONDON-NETO et al., 2001). A sucessão vegetal é um processo importante na recuperação de áreas degradadas para que o ambiente esteja em equilíbrio, sendo a dispersão de sementes a principal fonte constituinte do banco de sementes, responsável pela regeneração em áreas degradadas (GRIFFITH et al., 1996).

Segundo Campos e Ojeda (1997), a dispersão de frutos e sementes pode ser influenciada por diferentes fatores abióticos (vento, gravidade, água) e/ou bióticos (animais). O processo de dispersão, independente da forma de ocorrência, é muito complexo e envolve relações muito específicas entre plantas e agentes dispersores (FIGLIOLIA, 1993).

Pijl (1982) define essas síndromes como um conjunto de características, às vezes generalistas, às vezes restritas e precisas, que os propágulos apresentam, e que indicam o modo de dispersão das plantas. Com base nos critérios morfológicos descritos por Pij1 (1982), os diásporos são classificados em três grandes categorias: anemocóricos - diásporos adaptados à dispersão pelo vento; zoocóricos - diásporos adaptados à dispersão por animais como aves, morcegos e outros mamíferos; autocóricos - diásporos que não apresentam adaptação morfológica evidente para a dispersão pelas outras categorias, agrupando espécies barocóricas (dispersão por gravidade) e com dispersão explosiva.

O estudo das síndromes de dispersão das espécies vegetais, além de contribuir para o conhecimento da diversidade de um ambiente, traz informações importantes sobre os agentes dispersores, possibilitando entender as interações entre estes agentes e as plantas em frutificação, relação importante para compreensão da dinâmica do ecossistema onde estes organismos vivem.

Assim, esse tipo de estudo é necessário para indicar estratégias para preservação e uso sustentável dentro do plano de manejo de áreas como a Reserva Biológica Guaribas, a qual se trata de um fragmento de Mata Atlântica, um bioma com elevada diversidade e endemismo, constituindo um importante refúgio da fauna nativa da região. Como primeiro indicativo sobre a ecologia reprodutiva destas espécies e levando-se em consideração a importância das estratégias reprodutivas para comunidade, bem como a escassez de estudos desse tipo para a Mata Atlântica paraibana, torna-se importante o conhecimento sobre as síndromes de dispersão.

O objetivo deste trabalho foi estudar os aspectos morfológicos das sementes e/ou frutos das espécies ocorrentes na Reserva Biológica Guaribas para assim determinar as possíveis síndromes de dispersão destas espécies, relacionando-as ao hábito vegetacional. Além disso, determinar a frequência dos tipos de diásporos nas diversas famílias estudadas e determinar a disponibilidade de recursos para dispersores durante as estações seca e chuvosa, comparando-se os padrões de dispersão na vegetação estudada com aqueles encontrados em outras áreas de Mata Atlântica.

\section{Material e Métodos}

\section{Área de estudo}

A Reserva Biológica Guaribas (REBIO Guaribas) está localizada nos municípios de Mamanguape e de Rio

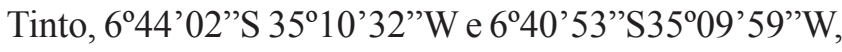
litoral norte do Estado da Paraíba, a $70 \mathrm{~km}$ da capital João Pessoa. A reserva é dividida em três fragmentos (chamados SEMAs I, II e III: Secretaria Estadual do Meio Ambiente) com 616 ha, 3,378 ha, e 327 ha em área, respectivamente (Figura 1). O clima da região é tropical úmido (Aw seguindo a classificação de Koppen), com uma estação chuvosa de fevereiro a outubro e uma estação seca de novembro a janeiro, com precipitação média mínima de $135.8 \mathrm{~mm}$ e máxima de $298.6 \mathrm{~mm}$, 
FIGURA 1: Localização da área de estudo, mostrando o litoral norte da Paraíba com os municípios de Mamanguape e Rio Tinto, destacando os três fragmentos de Mata Atlântica da Reserva Biológica Guaribas.

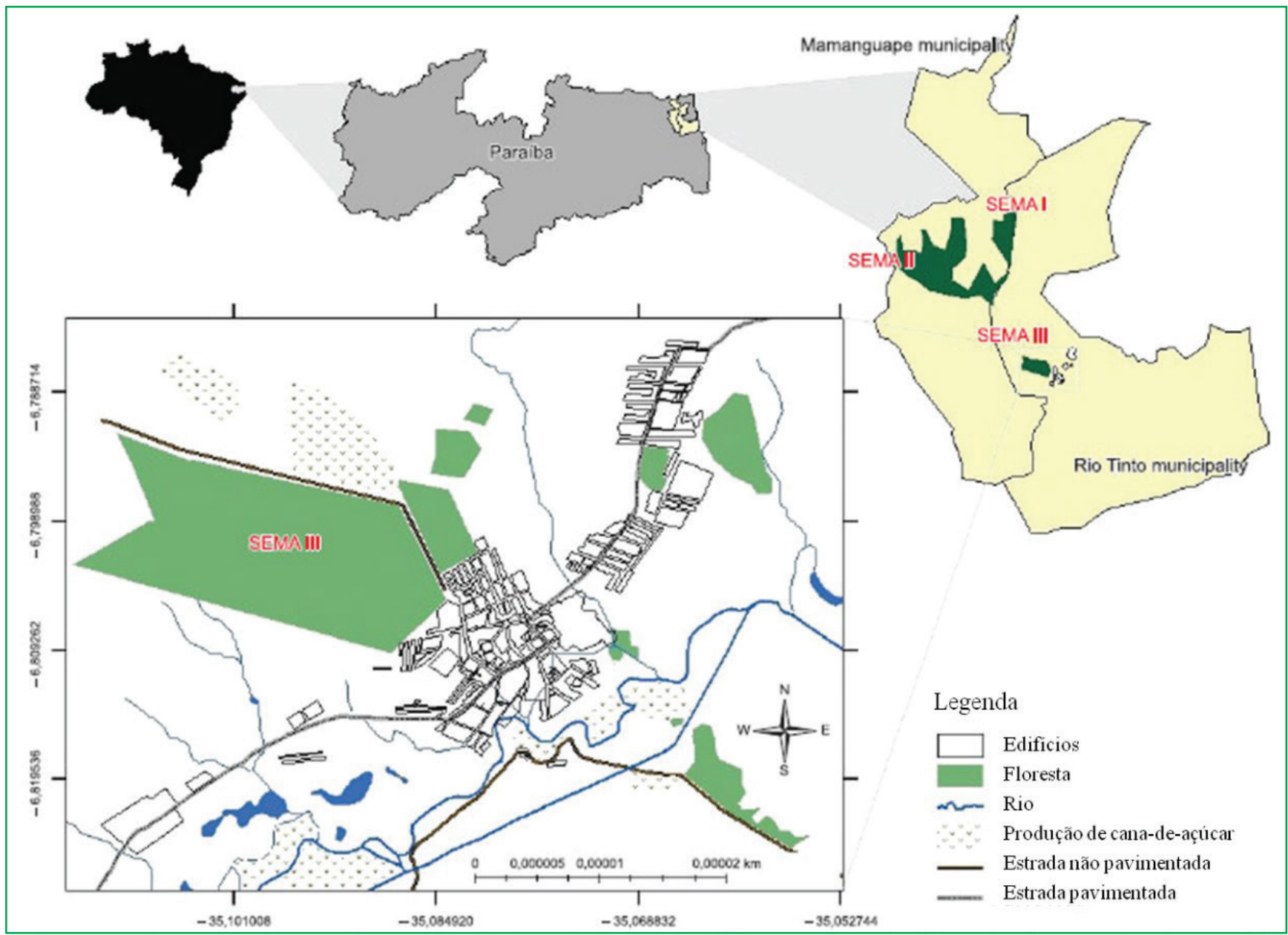

Fonte: França et al, 2012; Disponível em: <http://www.scielo.br/pdf/bn/v12n3/v12n3a19.pdf\#page=3\&zoom=auto,0,290">.

e média anual de precipitação $1.634 \mathrm{~mm}$ (BELTRÃO et al., 2005). O período com temperatura mais elevada compreende de dezembro a fevereiro, e a média anual de temperatura variando entre $24-36^{\circ} \mathrm{C}$ (MMA/ IBAMA, 2003). A vegetação local é constituída por remanescentes de Floresta Estacional Semidecidual e manchas de Cerrado, denominadas na região de Tabuleiros (OLIVEIRA-FILHO; CARVALHO, 1993). Esse estudo foi desenvolvido na SEMA II, por se tratar do maior remanescente de Mata Atlântica do estado Paraíba (MMA/IBAMA, 2003).

\section{Coleta de dados}

Os frutos foram coletados mensalmente, no período de setembro/07 a fevereiro/09 na Área II da REBIO
Guaribas, onde foram realizadas caminhadas em trilhas pré-existentes para coletar todos os diásporos das espécies vegetais que se encontravam em frutificação. Foram coletados entre 10 a 30 frutos por espécie para avaliar as características morfológicas. As características morfológicas referentes à coloração, odor, tamanho, peso, consistência, tipo e deiscência dos frutos foram analisadas no Laboratório de Ecologia Vegetal - UFPB. As medidas de tamanho dos frutos e sementes (diâmetro e comprimento) foram realizadas com paquímetro digital, e o peso dos frutos e sementes foi medido utilizando balança de precisão. Quando os frutos apresentavam-se dispostos em infrutescência, o diâmetro e o comprimento destas também eram calculados. Seguindo o modelo proposto por Pratt e Stiles (1985), o tamanho do fruto foi classificado em pequeno, quando apresentava até $5 \mathrm{~cm}$ de 
comprimento, médio, $5,1 \mathrm{~cm}$ até $12 \mathrm{~cm}$ de comprimento e, grande quando maior que $12 \mathrm{~cm}$.

Os diásporos que apresentavam consistência seca foram conservados a seco e os que possuíam consistência carnosa foram conservados em álcool $70 \%$. As espécies vegetais foram classificadas quanto ao hábito em arbórea, arbustiva, herbácea e trepadeira. Também foram coletados exemplares férteis para confecção de exsicatas incorporadas na coleção do Herbário "Lauro Pires Xavier" da Universidade Federal da Paraíba. Após analisar todas essas características determinou-se a síndrome de dispersão de cada espécie, seguindo o estabelecido por Pijl (1982).

\section{Resultados e Discussão}

Foram coletados 3.800 diásporos pertencentes a 136 espécies diferentes, distribuídas em 27 famílias (Figura 2). As famílias com o maior número de espécies foram Rubiaceae $(\mathrm{N}=8)$, Fabaceae $(\mathrm{N}=5)$ e Euphorbiaceae $(\mathrm{N}=5)$.
A síndrome mais abundante foi a zoocoria (58\%; $\mathrm{N}=79)$, seguida pela autocoria ( $29 \% ; \mathrm{N}=39$ frutos) e a anemocoria (13\%; $\mathrm{N}=18$ frutos) (Figura 3). Exemplos de espécies em cada categoria de síndrome de dispersão podem ser observados na (Figura 4).

Quanto às características morfológicas analisadas, a consistência carnosa prevaleceu com $54 \%(\mathrm{~N}=73)$ sobre a consistência seca, representada por $46 \%$ $(\mathrm{N}=63)$ (Tabela 1). A maior representatividade de frutos carnosos, que são dispersos por animais (zoocoria), é esperada em estudos na Mata Atlântica, devido ao padrão climático da área, o qual facilita a maior produção destes frutos (MORELLATO; LEITÃO FILHO, 1992; TABARELLI; PERES, 2002; ALMEIDA-NETO et al., 2008). Estima-se que cerca de $20 \%-50 \%$ das espécies de aves e mamíferos consomem frutos carnosos ao menos durante parte do ano (FLEMING, 1987). Na Mata Atlântica $87 \%$ de todas as árvores produzem frutos carnosos dispersos por animais, mas pode chegar a mais de 90\% em algumas áreas (CAMPASSI, 2006; GALETTI, 1996). O modo de dispersão parece variar de acordo com o gradiente de precipitação média

FIGURA 2: Número de espécies identificadas por família ocorrentes na SEMA II da Reserva Biológica Guaribas, PB, Brasil.

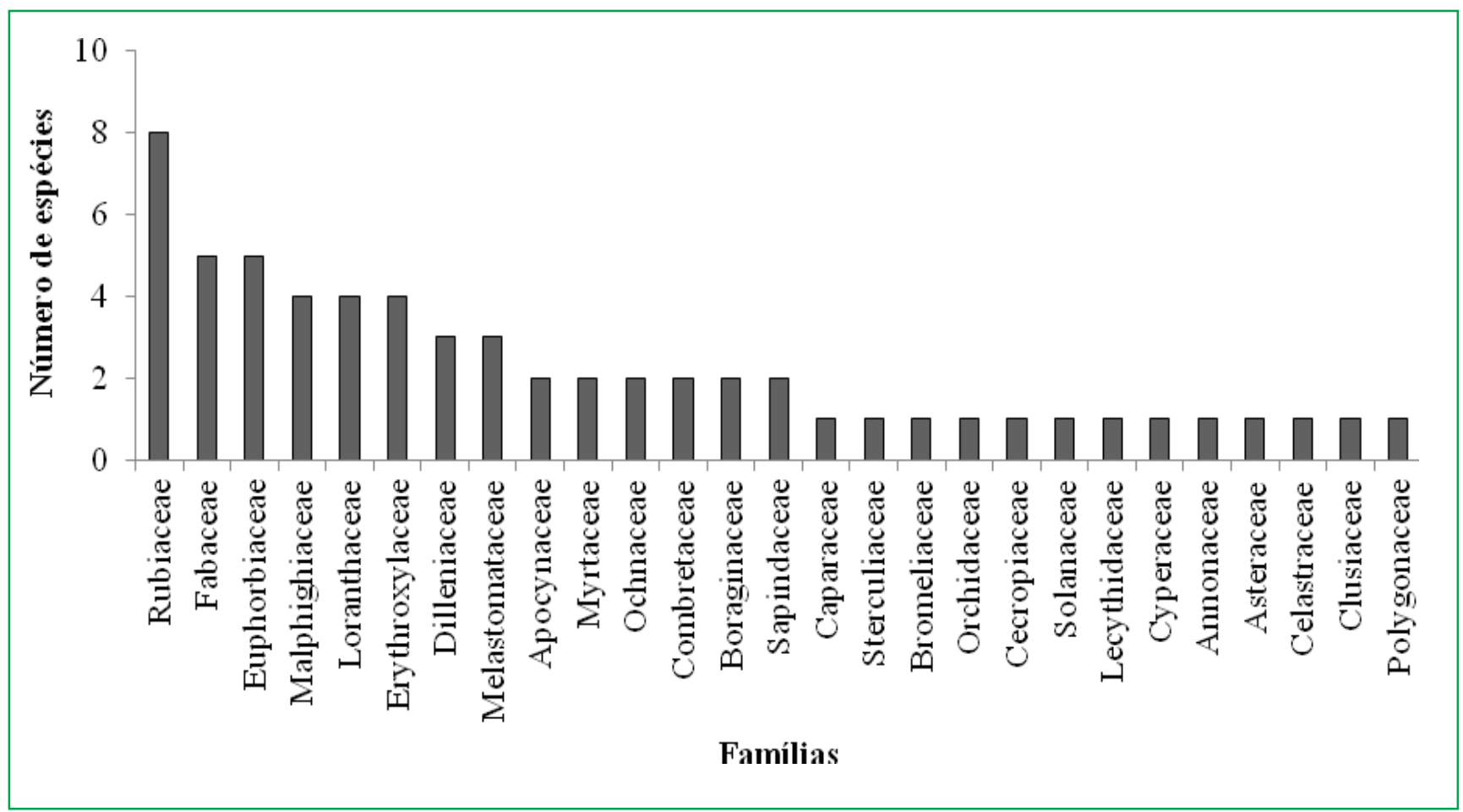


FIGURA 3: Síndromes de dispersão das espécies vegetais na SEMA II da Reserva Biológica Guaribas.

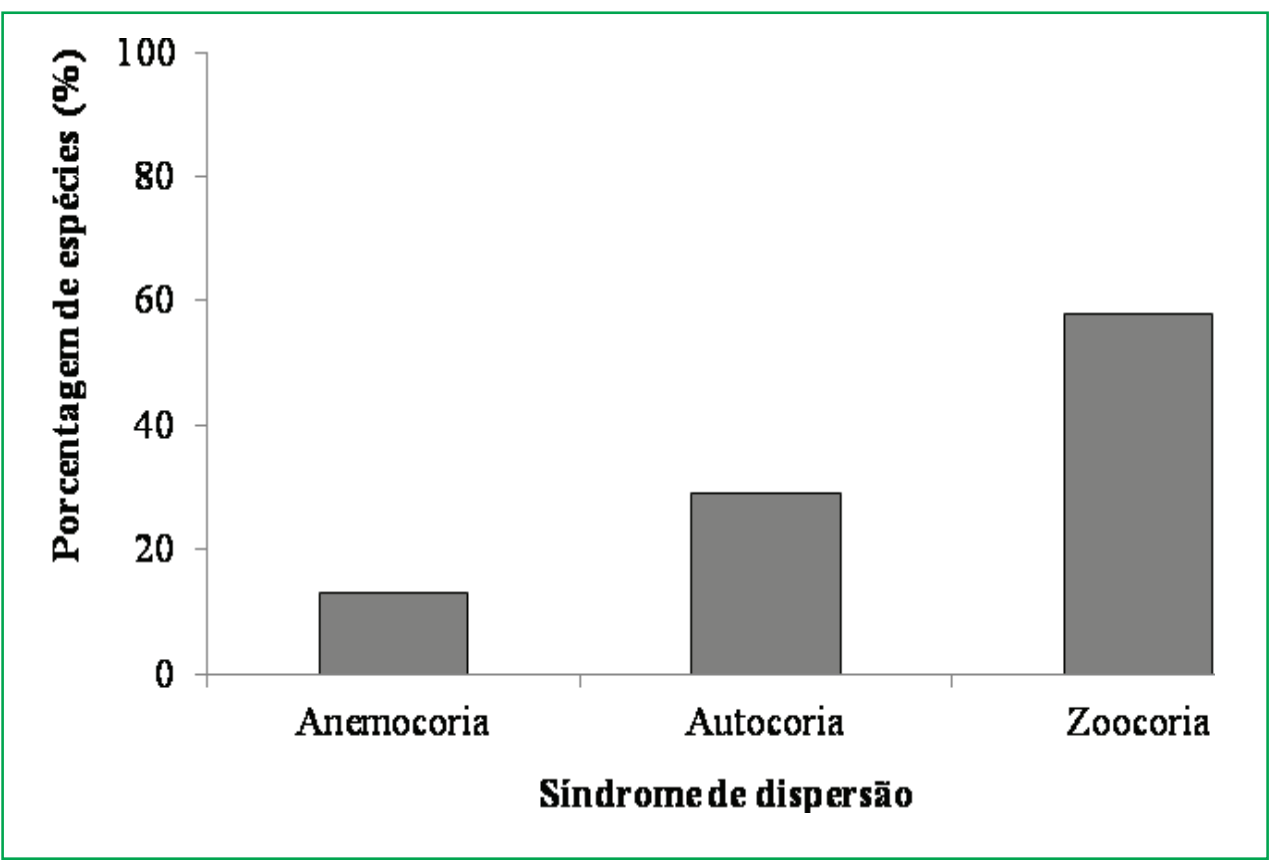

FIGURA 4: Diferentes diásporos ocorrentes em espécies vegetais na Reserva Biológica Guaribas, PB, Brasil. A. Fruto de Maytenus erythroxyla Reissek (síndrome de dispersão zoocórica); B. Fruto de Himatanthus obovatus (m. Arg.) Wood (síndrome de dispersão anemocórica); C. Fruto de Pithecellobiun cochliocarpum (Gomez) Macbr. (síndrome de dispersão autocórica).
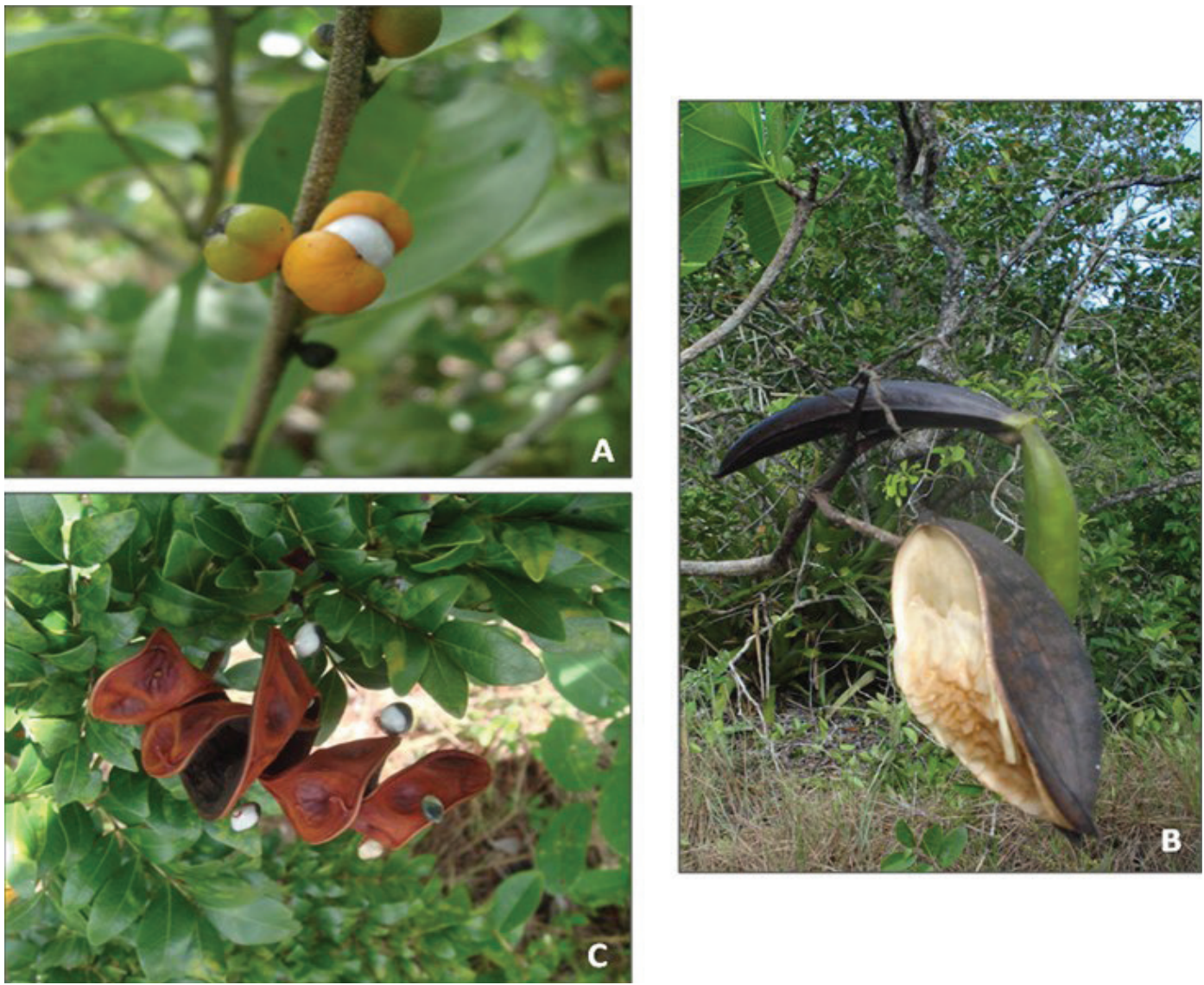
anual, sendo as espécies dispersas por vertebrados mais importantes em áreas mais úmidas (VICENTE et al., 2003), como a REBIO Guaribas.

Observou-se maior proporção de frutos com tamanho pequeno, cerca de 120 frutos (88\%), seguido dos frutos médios $(\mathrm{N}=9)$ e grandes $(\mathrm{N}=7)$. A predominância de frutos pequenos está relacionada ao tipo de dispersor, pois frutos menores que dois centímetros são consumidos mais facilmente por aves e os de tamanho maior são consumidos preferencialmente por mamíferos (HERRERA, 1989; 2002). A ocorrência de frutos carnosos e pequenos pode indicar o tipo de síndrome predominante, pois segundo Pijl (1982), os frutos dispersos por aves normalmente apresentam características como: tamanho pequeno e polpa rica em lipídeos ou proteínas.

Na Mata Atlântica nordestina, pelo menos 31,6\% das espécies de árvores possuem frutos maiores que 15 mm e grande parte das aves que poderiam dispersar esses frutos estão localmente extinta (SILVA; TABARELLI, 2000). Em seu trabalho com dispersão de sementes por vertebrados, Tabarelli e Peres (2002) afirmam que a grande abundância de frutos encontrados em fragmentos de Mata Atlântica pode estar relacionada com a falta de dispersores de grande porte, o que por pressão seletiva provoca a redução do tamanho dos frutos. A Reserva Biológica Guaribas está inserida em uma matriz de cana-de-açúcar, passando por um forte processo de perturbações antrópicas, acarretando na falta de vertebrados de grande e médio porte que poderiam atuar como dispersores. Dessa forma, a grande proporção de frutos pequenos encontrados nesta reserva pode sugerir uma mudança na estratégia de dispersão das espécies vegetais em reflexo da ausência desses dispersores. Em consequência da ausência ou baixa abundância de animais frugívoros nos fragmentos, o sucesso reprodutivo das plantas, medido pela remoção de seus frutos, pode ser drasticamente afetado (GALETTI et al., 2003).

A coloração verde foi predominante com $48 \%$ ( $\mathrm{N}=$ $65)$, seguida da cor marrom, $8 \%(\mathrm{~N}=11)$, do vermelho com $6 \%(\mathrm{~N}=8)$ e as demais cores, incluindo amarelo, rosa, preto e frutos multicoloridos representou $38 \%$, com 52 frutos (Tabela 1). Em relação à cor verde e ao vermelho, observou-se que os frutos carnosos predominaram sobre os secos, enquanto que os frutos secos destacaram-se apenas para a coloração marrom. Os frutos secos, na grande maioria, apresentam cores menos conspícuas devido à síndrome de dispersão ser predominantemente autocórica e/ou anemocórica, e não envolver agentes bióticos (Figura 5).

TABELA 1: Características morfológicas dos diásporos na SEMA II da Reserva Biológica Guaribas, PB, Brasil.

\begin{tabular}{llr}
\hline Característica & Padrão apresentado & \multicolumn{1}{c}{ N (\%) } \\
\hline \multirow{2}{*}{ Consistência } & Carnoso & $73(54 \%)$ \\
& Seco & $63(46 \%)$ \\
\hline \multirow{2}{*}{ Odor } & Ausente & $87(64 \%)^{*}$ \\
& Presente & $49(36 \%)$ \\
\hline \multirow{2}{*}{ Cor } & Verde & $65(48 \%)$ \\
& Marrom & $11(8 \%)$ \\
& Vermelho & $8(6 \%)$ \\
\multirow{2}{*}{ Tamanho } & Outras & $52(38 \%)$ \\
& Pequeno & $120(88 \%)$ \\
& Médio & $9(7 \%)$ \\
& Grande & $7(5 \%)$ \\
\hline
\end{tabular}

* os frutos observados quanto à presença de odor estavam maduros.

A maioria dos frutos carnosos apresentou coloração vermelho-alaranjado, o que pode estar relacionado à atratividade, pois estes diásporos apresentam cores que os destacam na mata e assim atraem os dispersores (CAZETTA et al., 2009). Fato comum no grupo das aves, que dispersam frutos conspícuos, com coloração variando entre o vermelho, o preto, o azul e a púrpura (PIJL, 1982; RODRIGUES, 1992; CAZETTA et al., 2009). Em frutos ornitócóricos, além da coloração do fruto, Cazetta et al. (2009) ressaltam a importância relativa de contrastes cromáticos utilizados pelas aves para detectar diásporos em condições naturais. Esses autores encontraram que contrastes cromáticos desempenham um importante papel nas interações entre aves e frutos, aumentando as chances de detecção destes frutos, provavelmente porque esses contrastes são sinais mais confiáveis para as aves sob diferentes condições luminosas. As espécies vegetais, portanto, podem aumentar as taxas de remoção e, indiretamente, o seu sucesso reprodutivo, produzindo frutos com cores que apresentem fortes contrastes cromáticos. 
FIGURA 5: Comparação entre a consistência e a coloração dos frutos coletados na Reserva Biológia Guaribas, PB, Brasil.

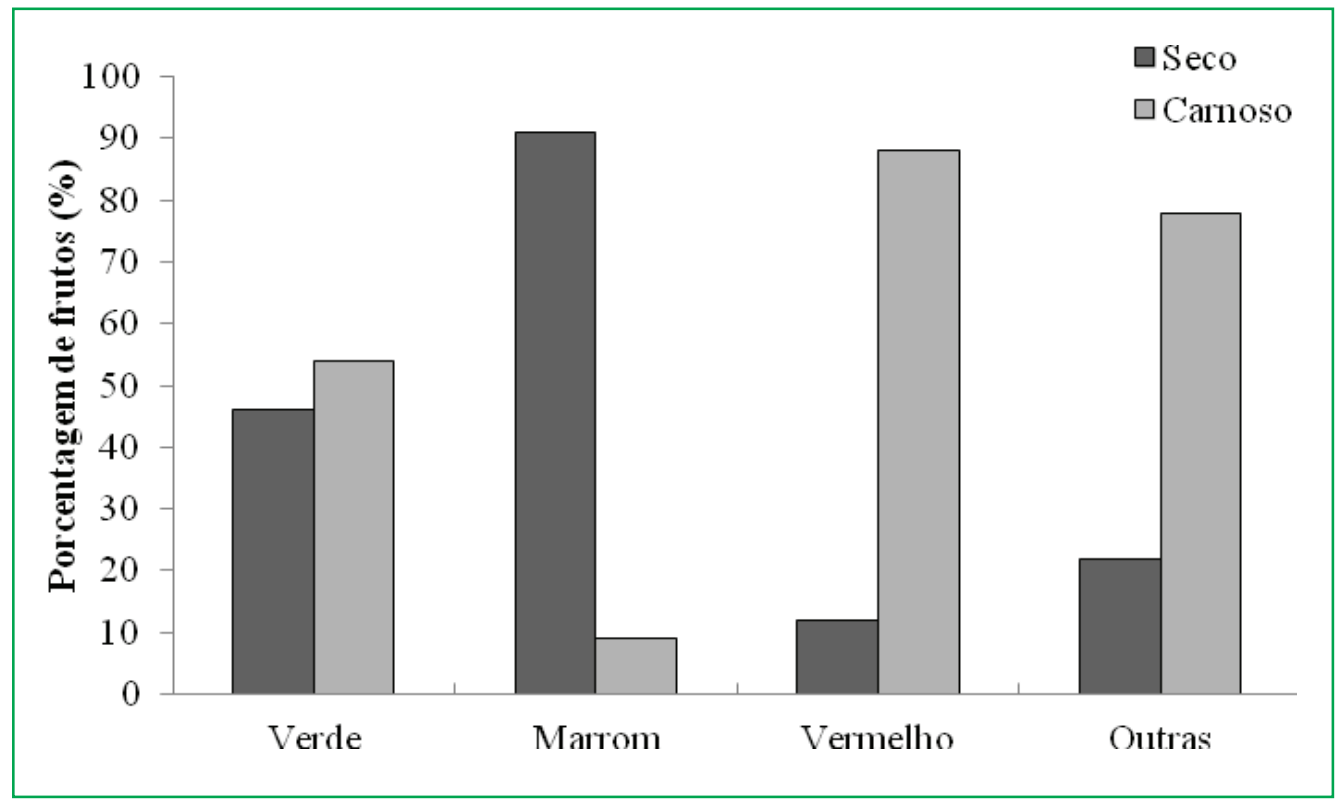

Observamos que os frutos da maioria das espécies (64\%) não apresentavam odor enquanto apenas 36\% apresentavam odor que variava entre adocicado ou azedo. A presença de odor é um caractere morfológico importante na identificação do dispersor de determinado fruto, pois, quando associado a outros caracteres, poderá atrair algumas espécies de mamíferos, répteis, no entanto, para as aves este não é um caractere importante, pois estas não possuem olfato aguçado (PIJL,1982).
Entre as espécies estudadas, o hábito arbustivo predominou com 71 espécies (52\%), para o hábito arbóreo observou-se 35 espécies (26\%), seguido do hábito herbáceo, com 18 espécies (13\%) e trepadeiras, com 12 espécies (9\%). Para os quatro hábitos observados, a síndrome zoocórica foi predominante, tendo 65\% (46 espécies) no hábito arbustivo, 54\% (19 espécies) para o hábito arbóreo, $50 \%$ (seis espécies) para trepadeiras e 45\% (oito espécies) para as herbáceas (Figura 6).

FIGURA 6: Relação entre o hábito da espécie e o tipo de síndrome de dispersão na Reserva Biológica Guaribas, PB, Brasil.

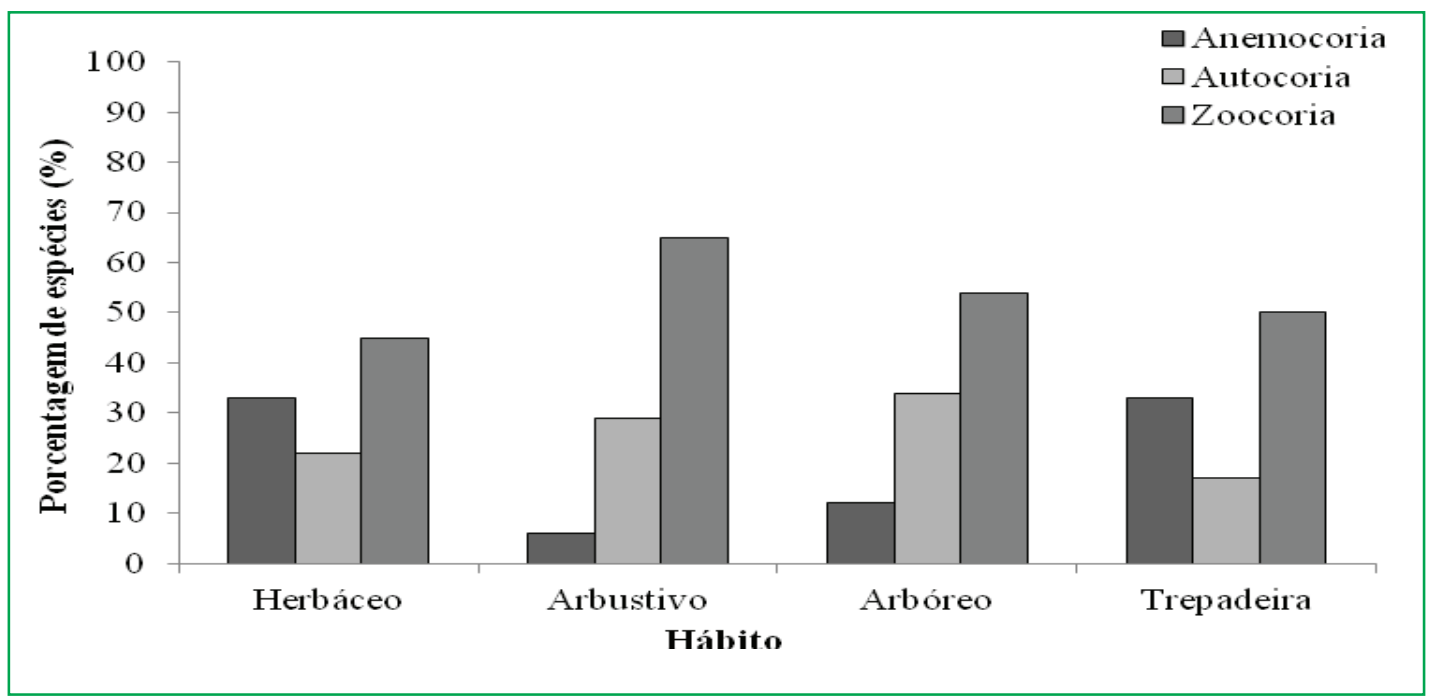


Segundo Jordano (2000), um grande número de árvores, trepadeiras e arbustos possuem frutos dispersos por animais. Sendo assim, as diferentes proporções de frutos carnosos produzidos por plantas com diferentes hábitos tornam-se importantes por diminuírem a sobreposição de nichos dos animais que dependem desses recursos.

Durante todo o período de estudo foram encontradas espécies em frutificação, disponibilizando recurso para os dispersores durante a estação seca (novembro a janeiro) e chuvosa (fevereiro a outubro) (Figura 7). A produção contínua de frutos ocorre por se tratar de um ambiente úmido, com precipitação média de $1.634 \mathrm{~mm}$, pois por não apresentar sazonalidade forte, e mesmo com a diminuição da precipitação, não impossibilita que as espécies produzam frutos carnosos.

Nesse fragmento houve a predominância de espécies com síndrome de dispersão zoocórica, assim como para outros estudos em florestas tropicais (GENTRY, 1982; MORELLATO; LEITÃO FILHO, 1992; VICENTE et al., 2003; TABARELLI; PERES, 2002; CAMPASSI, 2006). Esta síndrome está ligada diretamente à disponibilidade de recursos para a fauna, possibilitando a manutenção das espécies envolvidas neste tipo de interação, importante para dinâmica desse fragmento florestal. Na Mata Atlântica, aproximadamente $87 \%$ das espécies produzem frutos carnosos, podendo chegar a 90\% em algumas áreas (CAMPASSI, 2006; GALETTI, 1996). Wikander (1984) também relatou a anemocoria como predominante em uma floresta úmida na Venezuela e ainda ressaltou que esta síndrome foi mais abundante no estrato superior da floresta.

A contínua produção de frutos carnosos ao longo dos dois anos do estudo ressalta a importância da Reserva, um dos maiores fragmentos de Mata Atlântica na Paraíba, inserido em uma região onde este bioma está devastado. Representa uma importante fonte de recurso para atrair e manter a fauna na área da reserva. Outro ponto importante deste estudo foram as observações de agentes dispersores nos vegetais, mostrando a dinâmica florestal da REBIO Guaribas, reforçando sua importância para manutenção da biodiversidade regional.

Embora neste estudo tenham sido observadas as síndromes de dispersão, foi possível registrar várias visitas efetivas de agentes dispersores consumindo frutos, tais frutos quando possível foram coletados e analisados, apresentando como caracteres morfológicos tamanho pequeno, consistência carnosa, coloração conpíscua e com contraste cromático. Tais características culminam para síndrome ornitocórica, sendo verificada em campo pela presença da ave Dacnis cayana ingerindo

FIGURA 7: Curva do coletor das espécies em frutificação cujos diásporos foram coletados mensalmente na Reserva Biológica Guaribas, PB, Brasil.

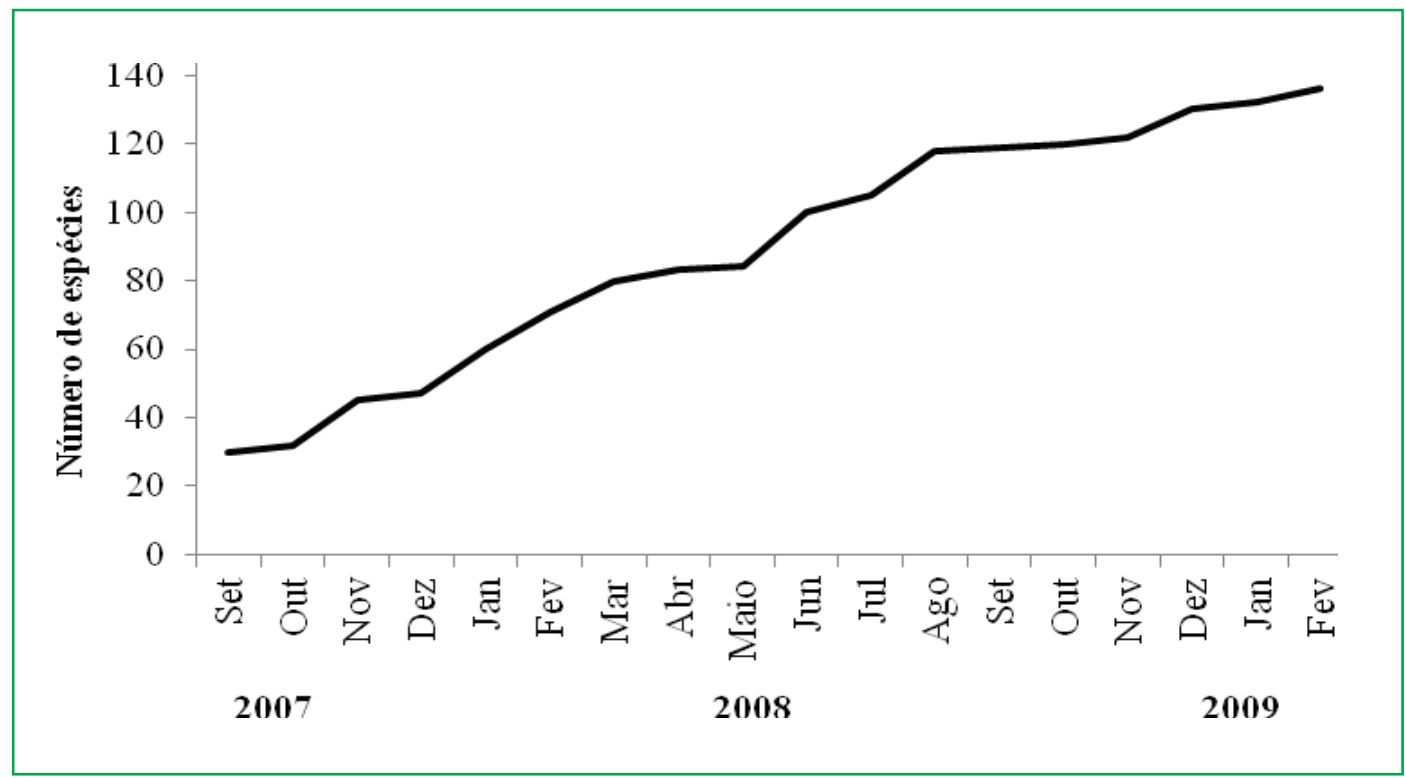


frutos inteiros de uma espécie de Celastraceae e uma Melastomataceae (Domingues, em preparação). A constatação da síndrome em campo ressalta a importância da manutenção desse fragmento, pois mostra que ainda existe uma dinâmica florestal, o que subsidia os processos de manutenção da biodiversidade regional.

\section{Referências}

ALMEIDA-NETO, M.; CAMPASSI, F.; GALETTI, M.; JORDANO, P.; OLIVEIRA-FILHO, A. Vertebrate dispersal syndromes along the Atlantic Forest: broad-scale patterns and macroecological correlates. Global Ecology and Biogeography, New Jersey, v. 17, n. 4, p. 503-513, 2008.

BELTRÃO, B. A.; MORAIS, F.; MASCARENHAS, J. C.; MIRANDA, J. L. F.; SOUZA JUNIOR, L. C.; MENDES, V. A. Projeto cadastro de fontes de abastecimento por água subterrânea estado de Paraíba. Diagnóstico do município de Rio Tinto. Recife: Ministério de Minas e Energia, Recife, 2005. 11 p.

CAMPASSI, F. Padrões geográficos das síndromes de dispersão e características dos frutos de espécies arbustivo-arbóreas em comunidades vegetais da Mata Atlântica. 2006. 84 f. Dissertação (Mestrado em Ecologia de Agroecossistemas) - Escola Superior de Agricultura Luiz de Queiroz, Piracicaba. 2006.

CAMPOS, C. M.; OJEDA, R. A. Dispersal and germination of Prosopis flexuosa (Fabaceae) seeds by desert mammals in Argentina. Journal of Arid Environments, London, v. 35, n. 4, p. 707-714, 1997.

CAZETTA, E.; SCHAEFER, H. M.; GALETTI, M. Why are fruits colorful? The relative importance of achromatic and chromatic contrasts for detection by birds. Evolutionary Ecology, London, v. 23, n. 2, p. 233-244, 2009.

FIGLIOLIA, M. B. Maturação de sementes de Inga uruguensis Hook et Arn associada à fenologia reprodutiva e a dispersão de sementes em floresta ripária do rio Mogi-Guaçu, município de Mogi-Guaçu. 1993. 150 f. Tese (Doutorado em Biologia Vegetal) - Universidade de São Paulo, São Paulo. 1993.

FLEMING, T. H. Patterns of tropical vertebrate frugivore diversity. Annual Review of Ecology and Systematics, Palo Alto, v. 18, n. 1, p. 91-109, 1987.

FRANÇA, R. C.; GERMANO, C. E. S.; FRANÇA, F .G. R. Composition of a snake assemblage inhabiting an urbanized area in the Atlantic Forest of Paraíba State, Northeast Brazil. Biota Neotropica, São Paulo, v. 12, p. 183-195 , 2012.

FRANKIE, G. W.; BAKER, H. G.; OPLER, P. A. Comparative phonological studies of trees in tropical wet and dry forests en the lowlands of Costa Rica. Journal of Ecology, London, v. 62, n. 3, p. 881-919, 1974.

GALETTI, M. 1996. Fruits and frugivores in a Brazilian Atlantic forest. 1996. $220 \mathrm{f}$. Tese (Doutorado em Biological Sciences) Universidade de Cambridge, Cambridge. 1996.
GAlleti, M.; COSTA, C.; CAZETTA, E. Effects of forest fragmentation, anthropogenic edges and fruit color on the consumption of ornithochoric fruits. Biological Conservation, Boston, v. 111, p. 269-293, 2003.

GENTRY, A. H. Patterns of neotropical plant species diversity. Evolutionary Biology, London, v. 15, n. 1, p. 1-84, 1982.

GRIFFITH, J. J.; DIAS, L. E.; JUCKSCH, I. Recuperação de áreas degradadas usando vegetação nativa. Saneamento Ambiental, São Paulo, v. 37, n. 7, p. 28-37, 1996.

HERRERA, C. M. Seed dispersal by animals: a role in Angiosperm diversification. American Naturalist, Chicago, v. 133, n. 3, p. 309$322,1989$.

HERRERA, C. M. Seed dispersal by vertebrates. In: HERRERA, C. M.; PELlMYR, O. (Ed.). Plant-animal interactions: an evolutionary approach. Malden: Blackwell Science, 2002. p. 185208.

HOWE, H. F. Aspects of variation in a neotropical seed dispersal system. Vegetatio, Perth, v. 107/108, n. 1, p. 149-162, 1993.

JORDANO, P. Fruits and frugivory. In: FENNER, M. (Ed.). Seeds: the ecology of regeneration in plant communities. Wallingford: Commonwealth Agricultural Bureau International, 2000. p. 125166.

MMA/IBAMA - MINISTÉRIO DO MEIO AMBIENTE/ INSTITUTO BRASILEIRO DO MEIO AMBIENTE E DOS RECURSOS NATURAIS RENOVÁVEIS. Plano de manejo da Reserva Biológica Guaribas. Brasília: CHESF, MRS Estudos Ambientais, 2003. 520 p.

MORELlATO, L. P. C.; LEITÃO FILHO, H. F. Padrões de frutificação e dispersão na Serra do Japi. In: MORELLATO, L. P. C. (Org.). História natural da Serra do Japi: ecologia e preservação de uma área florestal no Sudeste do Brasil. Campinas: UNICAMP/ FAPESP, 1992. p. 112-140.

OLIVEIRA-FILHO, A.T.; CARVALHO, D. A. Florística e fisionomia da vegetação no extremo norte do litoral da Paraíba. Revista Brasileira de Botânica, São Paulo, v. 16, n.1, p. 115-130, 1993.

PIJL, L. Principles of dispersal in higher plants. New York: Springer, 1982. $161 \mathrm{p}$.

PRATT, T. K.; STILLES, E. W. The influence of fruit size and structure on composition of frugivore assemblages in New Guinea. Biotropica, Maiden, v. 17, n. 4, p. 314-321, 1985.

RODRIGUES, M. G. Sazonalidade na dieta de vertebrados frugívoros em uma Floresta Semidecídua no Brasil. 1992. 104 f. Monografia (Especialização em Ciências Biológicas) Universidade Estadual de Campinas, Campinas. 1992.

RONDON-NETO, R. M.; WATZLAWICK, L. F.; CALDEIRA, M. V. W. Diversidade florística e síndromes de dispersão de diásporos das espécies arbóreas de um fragmento de floresta ombrófila mista. Revista Ciências Exatas e Naturais, Guarapuava, v. 3, n. 2, p. 209-216, 2001.

SILVA, J. M. C.; TABARELLI, M. Tree species impoverishment and the future flora of the Atlantic forest of northeast Brazil. Nature, London, v. 404, p. 72-74, 2000. 
TABARELLI, M.; PERES, C. A. Abiotic and vertebrate seed dispersal in the Brazilian Atlantic forest: implications for forest regeneration. Biological Conservation, Boston, v. 106, p. 165-176, 2002.

VICENTE, A.; SANTOS, A. M. M.; TABARELLI, M. Variação no modo de dispersão de espécies lenhosas em um gradiente de precipitação entre floresta seca e úmida no nordeste do Brasil. In: LEAL, I.; TABARELLI, M.; SILVA, J. M. C. (Ed.). Ecologia e conservação da caatinga. Recife: Ed. Universitária da UFPE. 2003. p. 565-592.

WIKANDER, T. Mecanismos de dispersión de diásporas de uma Selva Decídua en Venezuela. Biotropica, Maiden, v. 16, n. 4, p. 276-283, 1984. 